\title{
Leukocytes and creatinine may predict severity and guide management of ischemic colitis
}

\section{Sebastian Manuel Milluzzo a,b, Loredana Correalec, Guido De Marco d, Giulio Antonellic, Paola Cesaroa, Nicola Olivaria, Paolo Terragnolid, Tony Sabatinia , Cesare Hassanc, Cristiano Spada ${ }^{\mathrm{a}, \mathrm{b}}$}

Fondazione Poliambulanza Istituto Ospedaliero, Brescia; Fondazione Policlinico Universitario A. Gemelli IRCCS -Università Cattolica del Sacro Cuore, Rome; Nuovo Regina Margherita Hosptial, Rome, Italy

\section{Abstract}

${ }^{a}$ Digestive Endoscopy Unit and Gastroenterology, Fondazione Poliambulanza Istituto Ospedaliero, Brescia (Sebastian Manuel Milluzzo, Paola Cesaro, Nicola Olivari, Tony Sabatini, Cristiano Spada); ${ }^{b}$ Department of Gastroenterology, Fondazione Policlinico Universitario A. Gemelli IRCCS -Università Cattolica del Sacro Cuore, Rome (Sebastian Manuel Milluzzo, Cristiano Spada); 'Digestive Endoscopy Unit, Nuovo Regina Margherita Hospital, Rome (Loredana Correale, Giulio Antonelli, Cesare Hassan); 'Emergency Department, Fondazione Poliambulanza Istituto Ospedaliero, Brescia (Guido De Marco, Paolo Terragnoli), Italy

\section{Conflict of Interest: None}

Correspondence to: Sebastian Manuel Milluzzo, MD, Digestive Endoscopy Unit and Gastroenterology, Fondazione Poliambulanza Istituto Ospedaliero, Via L. Bissolati, 57, 25125 Brescia, Italy, e-mail: sebastian.m.milluzzo@gmail.com

Received 9 September 2020; accepted 30 October 2020; published online 16 January 2021

DOI: https://doi.org/10.20524/aog.2021.0577

\section{Introduction}

The term ischemic colitis (IC) was first coined by Marston et al [1] in 1966 to define an acute ischemic damage of the colonic wall, caused by an hypo-perfusion, usually followed by a reperfusion [2,3]. IC is a relatively common disease, with a reported incidence of 16.3 cases/100,000 person-years in the US [4] and a mortality rate ranging from 4-12\% [4-9]. IC affects more frequently adults, especially beyond the fifth decade of age, and females $[6,8,10]$.

Colonoscopy plays a major role in IC diagnosis, since it can directly observe the colonic mucosa and give precise anatomic limits of the colonic segments affected. Typical endoscopic findings of IC include edema, hyperemia, erosions, ulcers, and necrosis. On the basis of endoscopic findings, the management can vary from observation and supportive care in case of mild IC to hospitalization, bowel rest, total parenteral nutrition, 
antibiotic therapy or even surgical intervention in more severe cases [2].

So far, several studies have investigated factors able to predict the severity of IC, which include clinical characteristics, laboratory data, and endoscopic findings $[2,11]$, which can be used to discriminate patients and guide the clinician to the most appropriate management.

The primary aim of this study was to identify predictive factors of endoscopic severity of IC. Secondary endpoints were to evaluate the epidemiology, clinical presentation, endoscopic findings, and outcomes of IC.

\section{Patients and methods}

This is a retrospective analysis of a consecutive series of patients diagnosed with IC at Fondazione Poliambulanza Istituto Ospedaliero (Brescia, Italy) from January 2013 to December 2018. The cases were searched in the hospital database using codes 557.0 (acute vascular insufficiency of intestine), 557.9 (unspecified vascular insufficiency of intestine), and 557.1 (chronic acute vascular insufficiency of intestine) according to International Classification of Diseases, Ninth Revision, Clinical Modification (ICD-9-CM) [12].

An initial search identified a list of 399 patients. To avoid possible bias, patients who underwent urgent surgery at hospital admission due to colonic perforation (i.e., perforation due to acute diverticulitis, volvulus, or strangulated hernia) without a clear evidence of IC or patients with an inadequate documentation, were excluded. Finally, 227 patients with a definitive diagnosis of IC were included in the final evaluation.

All patients underwent colonoscopy performed according to our internal protocol, with $\mathrm{CO}_{2}$ insufflation after administration of cold enemas, in case of urgent colonoscopy, or high-dose (4 L) polyethylene glycol in case of elective colonoscopy. To assess distribution and phase of colitis, colonoscopy was performed reaching the most proximal segment affected by IC or, if technically possible, the cecum. Computed tomography (CT) scan was performed in selected cases to confirm diagnosis or to understand evolution of ischemic damage.

IC was graded using an internal score system, according to endoscopic results, evaluating extension and grade of damage. Grade 1 (Fig. 1) defined cases of hyperemia, erosions, small $(<1 \mathrm{~cm})$ and non-confluent ulcers; grade 2 (Fig. 2) defined cases of large $(>1 \mathrm{~cm})$ superficial, partially confluent ulcers; and grade 3 (Fig. 3 ) defined cases of deep ulcers or diffuse ulcers or necrosis. For the evaluation of predictive factors for severity, IC was grouped according to a binary variable into "minor ulcers" (Group A; grade 1) and "major ulcers" (Group B; grades 2 and 3 ) in order to compare homogenous groups and to analyze clinical or prognostic differences among them. The rationale behind the creation of this classification was to understand if endoscopic findings could be used as a surrogate of clinical severity. Therefore, endoscopic grading was compared with clinical (i.e., hypertension, ischemic heart disease, peripheral vascular disease, dyslipidemia), and laboratory (i.e., serum white blood cell count [WBC], creatinine, hemoglobin [Hb],

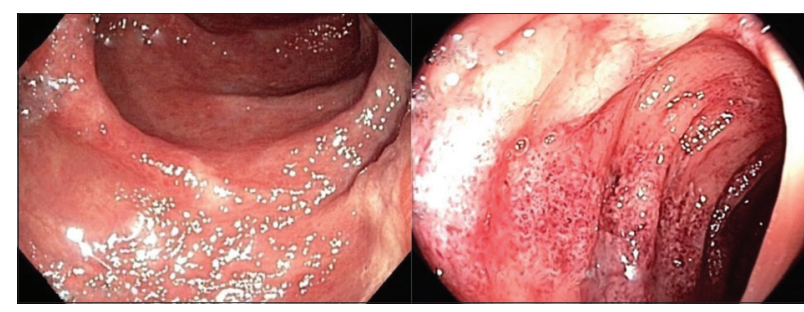

Figure 1 Grade 1 ischemic colitis

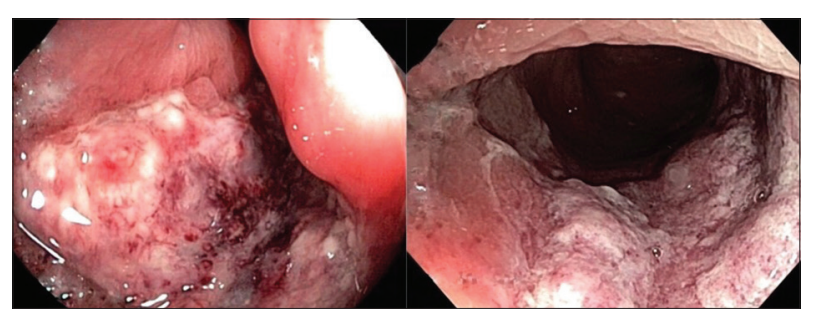

Figure 2 Grade 2 ischemic colitis

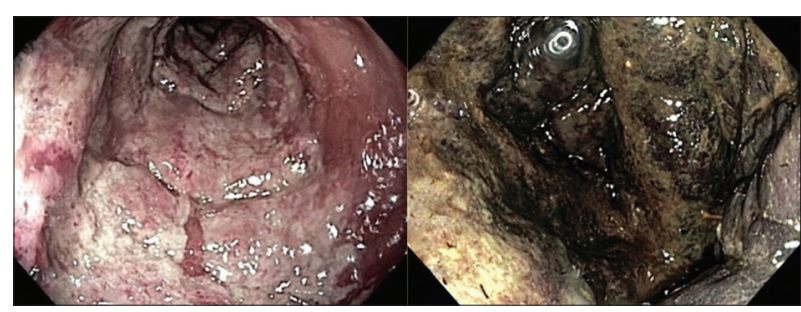

Figure 3 Grade 3 ischemic colitis

platelet count, serum lactate) risk factors of severity reported in the literature.

\section{Statistical analysis}

Descriptive variables were expressed as means with standard deviation (SD) and were compared using Student's $t$-test. Categorical variables were expressed as absolute numbers and proportions. The $\chi^{2}$ or Fisher tests were used for comparison of categorical variables as appropriate. For the analysis to identify predictive factors of severity, first, the ICs were separated according to a binary variable into "minor ulcers" (Group A; grade 1) and "major ulcers" (Group B; grades 2 and 3). Therefore, the IC scoring was considered a binary variable and univariate logistic regression analysis was used to examine for any association between IC and patient characteristics. For the purposes of this analysis, certain variables were collapsed into binary categories, as shown in Supplementary Appendix 1. The significant (at $\mathrm{P} \leq 0.1$ ) independent factors of IC grading were then entered into multivariate logistic regression analysis. A 2-sided P-value of $<0.05$ was considered statistically significant. Second, to further explore any variable, IC patients with either leukocytosis (WBC $\left.>10 \times 10^{9} / \mathrm{L}\right)$ or creatinine elevation $(\geq 1.5 \mathrm{mg} / \mathrm{dL})$ at hospital admission were included in the "abnormal" group, while the remaining patients without either leukocytosis or creatinine 
increase served as controls (i.e., normal group). Univariate and multivariate logistic regression analyses were used to determine if there was any association between the "abnormal" IC group (vs. normal) and study characteristics. Again, for the purposes of this analysis, certain variables were collapsed into binary categories, as shown in Supplementary Appendix 2.

\section{Results}

A total of 227 patients were included in the analysis; their mean age was $72.7 \pm 16.2$ years, and $73.6 \%$ of them were female (M:F ratio 60:167). Epidemiology, clinical presentation, endoscopic findings and outcomes of IC are shown in Table 1. IC presented with rectal bleeding in 194 patients (85.5\%), abdominal pain in 189 (83.3\%), diarrhea in 121 (53.3\%), and constipation in 7 (3\%). At emergency admission, 90 patients (39.6\%) presented with the classic "triad symptoms" (i.e., sudden cramping; abdominal pain followed by urgent desire to defecate; and then bloody diarrhea).

According to endoscopic results, IC was scored as: grade 1 in 137/227 (60.4\%); grade 2 in 62/227 (27.3\%); and grade 3 in the remaining 28 (12.3\%) cases. IC involved rectum, sigmoid, descending, transverse and right colonic segments in $7.5 \%$, $65.5 \%, 67 \%, 12.8 \%$ and $0.9 \%$, respectively.

At univariate analysis (Table 2) patients' significant factors (at $\mathrm{P} \leq 0.1$ ) associated with endoscopic high-grade IC (Group $\mathrm{B}$; grades 2 and 3 ) were age (74.9 vs. $71.3 ; \mathrm{P}=0.09$ ), diabetes (14.4\% vs. $12.4 \% ; \mathrm{P}=0.09$ ), and leukocytosis or creatinine elevation ( $74.4 \%$ vs. $60.6 \%$; $\mathrm{P}=0.032$ ).

At multivariate analysis (Table 3), patients with either leukocytosis $(143 / 227,63.0 \%)$ or creatinine elevation $(34 / 227$, $15.0 \%)$ were included in the "abnormal group" (150/227; $66 \%$ ) and were compared with the remaining 77 patients ("normal group") without alterations in the WBC or creatinine levels, showing a significant association with high-grade IC at colonoscopy ( $44.7 \%$ vs. $29.9 \%$; odds ratio [OR] $1.92,95 \%$ confidence intervals [CI] 1.07-3.52; $\mathrm{P}=0.030$ ).

\section{Risk factors}

Risk factors associated with IC were: hypertension in 144 patients (63.4\%), ischemic vascular disease in 80 (35.8\%), dyslipidemia in $65(28.6 \%)$, diabetes in 30 (13.2\%), active smoking in $20(8.8 \%)$, and use of oral contraceptives in 5 (0.9\%). A history of IC was found in $11 \%$ of all patients, with no statistically significant differences among the groups $(\mathrm{P}=0.225)$.

\section{Outcomes}

All patients were hospitalized. The median length of stay was 5.2 days, with a range of 3-11 days. None of the patients included in this analysis underwent surgery during hospital
Table 1 Epidemiology, clinical presentation, endoscopic findings and outcomes of ischemic colitis

\begin{tabular}{|c|c|c|}
\hline Characteristics & & Value \\
\hline \multirow[t]{2}{*}{ Patients } & Total (male:female) & $227(60: 167)$ \\
\hline & Age, mean $( \pm S D)$, years & $72.7 \pm 16.2$ \\
\hline \multirow[t]{7}{*}{ Risk factors } & Hypertension, $\mathrm{n}(\%)$ & $144(63.4 \%)$ \\
\hline & Ischemic vascular disease, $\mathrm{n}(\%)$ & $80(35.8 \%)$ \\
\hline & Dyslipidemia, n (\%) & $65(28.6 \%)$ \\
\hline & Diabetes, n (\%) & $30(13.2 \%)$ \\
\hline & Previous ischemic colitis, $\mathrm{n}(\%)$ & $25(11 \%)$ \\
\hline & Smoking, n (\%) & $20(8.8 \%)$ \\
\hline & Oral contraceptive, n (\%) & $5(0.9 \%)$ \\
\hline \multirow{5}{*}{$\begin{array}{l}\text { Clinical } \\
\text { presentation }\end{array}$} & Rectal bleeding, n (\%) & $194(85.5 \%)$ \\
\hline & Abdominal pain, n (\%) & $189(83.3 \%)$ \\
\hline & Diarrhea, n (\%) & $121(53.3 \%)$ \\
\hline & Typical $^{*}$ symptoms, n (\%) & $90(39.6 \%)$ \\
\hline & Costipation, n (\%) & $7(3 \%)$ \\
\hline \multirow{3}{*}{$\begin{array}{l}\text { Endoscopic } \\
\text { score }\end{array}$} & Grade $1, \mathrm{n}(\%)$ & $137(60.4 \%)$ \\
\hline & Grade 2, n (\%) & $62(27.3 \%)$ \\
\hline & Grade 3, n (\%) & $28(12.3 \%)$ \\
\hline \multirow{5}{*}{$\begin{array}{l}\text { Colonic } \\
\text { involvement }\end{array}$} & Rectum, n (\%) & $17(7.5 \%)$ \\
\hline & Sigmoid, n (\%) & $149(65.6 \%)$ \\
\hline & Descending, n (\%) & $152(67 \%)$ \\
\hline & Transverse, n (\%) & $29(12.8 \%)$ \\
\hline & Right, n (\%) & $2(0.9 \%)$ \\
\hline \multirow[t]{2}{*}{ Outcomes } & $\begin{array}{l}\text { Hospital stay, median (range), } \\
\text { days }\end{array}$ & $5.2(3-11)$ \\
\hline & Deaths, n (\%) & $3(1.3 \%)$ \\
\hline
\end{tabular}

* = sudden cramping abdominal pain followed by urgent desire to defecate and then bloody diarrhea

$S D$, standard deviation

stay. Death occurred in 3 patients (1.3\%): an 83-year-old female died of a septic shock due to grade 1 IC located in the transverse colon; a 102-year-old female died of a hemorrhagic shock due to grade 3 IC located in the rectum; and an 88-yearold male died of a septic shock due to grade 3 IC located in the sigmoid colon.

\section{Discussion}

Among the different variables analyzed in this study, leukocytosis and/or creatinine elevation at hospital admission were found to be significantly related with a more severe colonic involvement in patients with IC. They might be useful in clinical practice to stratify patients, avoiding unnecessary colonoscopies in patients without other risk factors (i.e., age and diabetes). 
Table 2 Univariate analysis comparing demographic and clinical characteristics according to endoscopic grading of ischemic colitis: Group A (“minor ulcers") vs. group B ("major ulcers")

\begin{tabular}{|c|c|c|c|c|c|}
\hline Characteristics & $\begin{array}{l}\text { Entire population } \\
\qquad(\mathrm{n}=227)\end{array}$ & $\begin{array}{c}\text { Grade } 2 \text { or } 3 \text {, } \\
\text { Group B }(n=90)\end{array}$ & $\begin{array}{l}\text { Grade 1, } \\
\text { Group A }(n=137)\end{array}$ & OR $(95 \% \mathrm{CI})$ & P-value \\
\hline \multicolumn{6}{|l|}{ Age } \\
\hline mean $( \pm S D)$ years & $72.7( \pm 16.2)$ & $74.9( \pm 15.7)$ & $71.3( \pm 16.4)$ & $1.01(1.00-1.03)$ & 0.098 \\
\hline \multicolumn{6}{|l|}{ Diabetes, n (\%) } \\
\hline Yes & $30(13.2)$ & $13(14.4)$ & $17(12.4)$ & 1 & \\
\hline No & $197(86.8)$ & $77(85.6)$ & $120(87.6)$ & $0.44(0.16-1.07)$ & 0.090 \\
\hline \multicolumn{6}{|c|}{ Leukocytosis or creatinine elevation, $n$ (\%) } \\
\hline No & $77(33.9)$ & $23(25.6)$ & $54(39.4)$ & 1 & \\
\hline Yes & $150(66.1)$ & $67(74.4)$ & $83(60.6)$ & $1.90(1.07-3.44)$ & 0.032 \\
\hline
\end{tabular}

Table 3 Multivariate analysis comparing IC grades (dichotomized) according to leukocyte count and creatinine levels (abnormal, either leukocytosis or serum creatinine elevation at hospital admission, $\mathrm{n}(\%)$ vs. normal, patients without alteration of leukocytes count and creatinine)

\begin{tabular}{lcccc}
\hline Characteristics & Entire population ( $\mathrm{n}=227)$ & Abnormal $(\mathrm{n}=150)$ & Normal 1 (77) & OR (95\%CI) \\
\hline IC grade (dichotomized), $\mathrm{n}(\%)$ & & & & \\
1 & $137(60.4)$ & $83(55.3)$ & $54(70.1)$ & 1 \\
2 or 3 & $90(39.6)$ & $67(44.7)$ & $23(29.9)$ & $1.92(1.07-3.52)$ \\
\hline OR, odd ratio; CI, confidence interval; IC, ischemic colitis; leukocytosis, leukocytes count $>10 \times 109 / \mathrm{L}$; creatinine elevation, creatinine $\geq 1.5 \mathrm{mg} /$ dL
\end{tabular}

Factors able to predict the severity of IC, which have been evaluated in the literature so far, are summarized in Table 4 [4-7,9,13-17]. Among these, laboratory tests seem particularly useful in the clinical practice to guide the management of these patients. Mosele et al [16] showed that urea $(14.5 \pm 8.9$ vs. $8.2 \pm 5.3 \mathrm{mmol} / \mathrm{L} ; \mathrm{P}=0.02)$ and $\mathrm{LDH}(459 \pm 97$ vs. $272 \pm 88.7 \mathrm{U} / \mathrm{L} ; \mathrm{P}=0.007)$ are more frequently abnormal in severe IC. Montoro et al [7] showed that patients with severe IC had a higher frequency of WBC $>15 \times 10^{9} / \mathrm{L}, \mathrm{Hb}<12 \mathrm{~g} / \mathrm{dL}$, and albumin $<2.8 \mathrm{~g} / \mathrm{L}$. A retrospective study by Añón et al [15] showed that anemia $(\mathrm{Hb}<12 \mathrm{~g} / \mathrm{dL}, 37.5 \%$ vs. $10.1 \%$; $\mathrm{P}=0.012)$ and hyponatremia (serum $\mathrm{Na}<136 \mathrm{mEq} / \mathrm{L}, 46.6 \%$ vs. $14.9 \%$; $\mathrm{P}=0.012$ ) were more frequently detected in patients with severe disease. Huguier et al [13] reported that serum bicarbonate level $(<24 \mathrm{mmol} / \mathrm{L})$ was independently associated with severe IC $(\mathrm{P}=0.03)$.

In this study, at univariate analysis, patients' factors significantly associated with high grade IC were age (74.9 vs. $71.3 ; \mathrm{P}=0.09$ ), diabetes ( $14.4 \%$ vs. $12.4 \% ; \mathrm{P}=0.09)$, and leukocytosis or creatinine elevation $(74.4 \%$ vs. $60.6 \%$; $\mathrm{P}=0.032)$ at hospital admission. At multivariate analysis, leukocytosis or creatinine elevation were found to remain significantly associated with a higher grade of IC at colonoscopy (44.7\% vs. 29.9\%; OR 1.92, 95\%CI 1.07-3.52; $\mathrm{P}=0.030$ ). The identification of such predictive factors can be clinically relevant since both WBC and serum creatinine are cheap and routinely performed at the emergency unit. Therefore, they might be useful in clinical practice to identify patients who can benefit from an early discharge without additional diagnostic tests and to indicate those who deserve colonoscopy and hospitalization.

As secondary endpoints, the present series confirms the results previously described in the literature $[4,6-8,10,18-20]$. As an example, the majority of patients were female $(73.6 \%)$ and elderly ( $72.2 \pm 16.2$ years old) and were affected by hypertension (63.4\%), ischemic vascular disease $(35.8 \%)$, dyslipidemia (28.6\%), and diabetes (13.2\%) as comorbidities [4-6,8,9,21]. Moreover, recurrence of IC (11\%) is also comparable to that reported in the literature, which ranges from $6.8-16.0 \%[6,13,22,23]$. On the other hand, it is surprising that only 20 patients $(8.8 \%)$ in the present series had an active smoking history at hospital admission. However, bias cannot be excluded due to the retrospective nature of the study.

Similar results were also obtained in terms of clinical presentation [2,5-7], since IC manifested with rectal bleeding, abdominal pain, diarrhea and the typical "triad" of symptoms in $85.5 \%, 83.3 \%, 53.3 \%$ and $39.6 \%$, respectively, and colonic segmental distribution was similar to that reported in the literature [4-7], since the descending and sigmoid colon were the most commonly affected (67\% and $65.6 \%$, respectively).

This study has certainly some limitations. Although we aimed to collect a consecutive series, the lack of a unique coding of identification in ICD prevents an accurate inclusion of the patients to establish the real incidence of IC. In addition, the retrospective design of the study may be responsible for biases. However, to limit such potential biases, a rigorous analysis of the available data was performed. Inadequate information was limited through a meticulous research in the hospital database, 
Table 4 studies evaluating risk factor of severity of ischemic colitis

\begin{tabular}{|c|c|c|c|c|c|c|}
\hline Author & Year of publication & Study design & Patients & Risk factors & Odd ratio $(95 \% \mathrm{CI})$ & P-value \\
\hline \multirow[t]{3}{*}{ Huguier [13] } & 2006 & $\mathrm{R}$ & 73 & Age $<80$ years & N/A & 0.008 \\
\hline & & & & Male & N/A & 0.05 \\
\hline & & & & Bicarbonate $<24 \mathrm{mmol} / \mathrm{L}$ & N/A & 0.03 \\
\hline \multirow[t]{2}{*}{ Añón [15] } & 2006 & $\mathrm{R}$ & 85 & $\mathrm{Hb}<12 \mathrm{~g} / \mathrm{dL}$ & $5.31(1.47-19.08)$ & 0.010 \\
\hline & & & & $\mathrm{Na}<136 \mathrm{mEq} / \mathrm{L}$ & $4.98(1.47-16.8)$ & 0.012 \\
\hline \multirow[t]{3}{*}{ Longstreth [6] } & 2009 & $\mathrm{R}$ & 401 & Male & $2.65(1.00-7.05)$ & 0.05 \\
\hline & & & & COPD & $3.13(2.06-4.75)$ & $<0.0001$ \\
\hline & & & & Diabetes mellitus & $1.82(1.31-2.53)$ & 0.0004 \\
\hline Brandt [5] & 2010 & $\mathrm{R}$ & 313 & COPD & $2.70(2.34-3.06)$ & $<0.01$ \\
\hline Chung [17] & 2010 & $\mathrm{P}$ & 173 & Ulceration & $2.30(1.49-3.11)$ & 0.005 \\
\hline \multirow[t]{5}{*}{ Cubiella Fernández [9] } & 2010 & $\mathrm{R}$ & 483 & Atherosclerosis & $4.10(1.32-12.76)$ & 0.01 \\
\hline & & & & Heart failure & $3.17(1.31-7.69)$ & 0.01 \\
\hline & & & & Dyslipidemia & $2.13(1.27-3.58)$ & 0.004 \\
\hline & & & & Diabetes mellitus & $1.76(1.01-3.08)$ & 0.046 \\
\hline & & & & Peripheral arteriopathy & $4.09(1.32-12.72)$ & 0.01 \\
\hline \multirow[t]{2}{*}{ Lee [14] } & 2010 & $\mathrm{R}$ & 77 & Male & $9.50(1.8-51.2)$ & $<0.01$ \\
\hline & & & & Chronic kidney disease & $8.50(1.2-58.8)$ & 0.03 \\
\hline \multirow[t]{2}{*}{ Mosele [16] } & 2010 & $\mathrm{R}$ & 46 & Urea $>10 \mathrm{mmol} / \mathrm{L}$ & $4.35(1.1-16.8)$ & 0.02 \\
\hline & & & & $\mathrm{LDH}>450 \mathrm{U} / \mathrm{L}$ & $14.25(1.5-138.2)$ & 0.007 \\
\hline \multirow[t]{3}{*}{ Montoro [7] } & 2011 & $\mathrm{P}$ & 364 & $\mathrm{WBC}>15 \times 10^{9} / \mathrm{L}$ & N/A & $<0.01$ \\
\hline & & & & $\mathrm{Hb}<12 \mathrm{~g} / \mathrm{dL}$ & $4.50(1.8-10.7)$ & $<0.001$ \\
\hline & & & & Albumin $<2.8 \mathrm{~g} / \mathrm{L}$ & N/A & 0.01 \\
\hline \multirow[t]{3}{*}{ Yadav [4] } & 2015 & $\mathrm{R}$ & 445 & Male & $1.4(1.1-1.8)$ & 0.022 \\
\hline & & & & Age $\geq 40$ years & $5.8(1.3-25.2)$ & $<0.001$ \\
\hline & & & & COPD & $2.8(2.1-3.7)$ & $<0.001$ \\
\hline
\end{tabular}

$R$, retrospective; $P$, prospective; $C O P D$, chronic obstructive pulmonary disease; $W B C$, white blood cell; $L D H$, lactate dehydrogenase; Hb, hemoglobin; Na, sodium; N/A, not available

excluding patients with missing data. This may represent a limitation since the final analysis was performed in a "selected" subgroup of patients. However, lack of complete information caused the exclusion of only 19 of 246 patients that, although relevant, does not seem to represent a crucial limit which can affect the overall results of the study. Moreover, patients who underwent urgent surgery due to colonic perforation without a clear evidence of IC were excluded. This could result in a selection of a "non-surgical" subgroup of patients which might not be completely representative of the whole IC population. Furthermore, other comorbidities not evaluated in the analysis could also have influenced the severity of IC. Larger prospective studies could better address this point.

Moreover, once IC is suspected, CT scan is considered by the 2015 American College of Gastroenterology guidelines [2] as the first imaging modality to assess distribution and phase of colitis [24-26]. However, CT findings are not pathognomonic and, therefore, the same guidelines suggest to consider an early colonoscopy (within $48 \mathrm{~h}$ of presentation) to confirm the diagnosis [2]. In the present series, colonoscopy was largely used as the first diagnostic approach due to the high number of rectal bleeding and diarrhea at hospital admission. CT scan was performed only in case of clinical instability or worsening clinical conditions.

In conclusion, the present series confirms that IC mostly affects female and elderly patients, often presenting with a typical "triad" of symptoms. The common cardiovascular risk factors play a central role in the pathophysiology. Endoscopic findings ranged from erythema and erosion in the low-grade IC to deep ulcers and necrosis in the high-grade IC. Outcomes in terms of length of stay, complications and mortality were similar among the groups. Colonoscopy has a limited role and it does not modify the clinical outcome. Although confounding factors cannot be excluded due to the study design and patients' characteristics, leukocytosis and/or creatinine elevation at hospital admission were found to be significantly related with a more severe IC. Consequently, these laboratory tests might be used to stratify patients and to indicate when colonoscopy and 
hospitalization may be necessary. Further larger prospective trials are needed to confirm these data. In this setting, a costeffectiveness analysis could be useful.

\section{Summary Box}

\section{What is already known:}

- Ischemic colitis (IC) is a relatively common disease, mostly affecting female patients

- Cardiovascular disease and diabetes mellitus are the most frequent risk factors associated with IC

- Laboratory testing can be useful to predict IC severity

\section{What the new findings are:}

- Leukocytosis or creatinine elevation at hospital admission were significantly associated with a higher grade of IC at colonoscopy

- Age and diabetes were shown to be significantly associated with high-grade IC at colonoscopy

- Leukocytosis or creatinine elevation at hospital admission can be used to stratify patients for the need of endoscopy and hospitalization

\section{References}

1. Marston A, Pheils MT, Thomas ML, et al. Ischaemic colitis. Gut 1966;7:1-15.

2. Brandt LJ, Feuerstadt P, Longstreth GF, et al. ACG clinical guideline: epidemiology, risk factors, patterns of presentation, diagnosis, and management of colon ischemia (CI). Am J Gastroenterol 2015;110:18-44; quiz 45.

3. Doulberis M, Panagopoulos P, Scherz S, et al. Update on ischemic colitis: from etiopathology to treatment including patients of intensive care unit. Scand J Gastroenterol 2016;51:893-902.

4. Yadav S, Dave M, Edakkanambeth Varayil J, et al. A populationbased study of incidence, risk factors, clinical spectrum, and outcomes of ischemic colitis. Clin Gastroenterol Hepatol 2015;13:731-738.e1-e6; quiz e41.

5. Brandt LJ, Feuerstadt P, Blaszka MC. Anatomic patterns, patient characteristics, and clinical outcomes in ischemic colitis: a study of 313 cases supported by histology. Am J Gastroenterol 2010;105:2245-2252; quiz 2253.

6. Longstreth GF, Yao JF. Epidemiology, clinical features, highrisk factors, and outcome of acute large bowel ischemia. Clin Gastroenterol Hepatol 2009;7:1075-1080.e1-e2; quiz 1023.

7. Montoro MA, Brandt LJ, Santolaria S, et al. Clinical patterns and outcomes of ischaemic colitis: results of the Working Group for the Study of Ischaemic Colitis in Spain (CIE study). Scand J Gastroenterol 2011;46:236-246.

8. Paterno F, McGillicuddy EA, Schuster KM, et al. Ischemic colitis: risk factors for eventual surgery. Am J Surg 2010;200:646-650.

9. Cubiella Fernández J, Núñez Calvo L, González Vázquez E, et al. Risk factors associated with the development of ischemic colitis. World J Gastroenterol 2010;16:4564-4569.

10. Suh D-C, Kahler KH, Choi I-S, et al. Patients with irritable bowel syndrome or constipation have an increased risk for ischaemic colitis. Aliment Pharmacol Ther 2007;25:681-692.

11. Seo HI, Choi K, Han KH, et al. Predisposing factors of ischemic colitis: data from 14 years of experience in a single center. Gastroenterol Res Pract 2017;2017:1049810.

12. ICD - ICD-9-CM - International Classification of Diseases, Ninth Revision, Clinical Modification. 2019; Available from: https:// www.cdc.gov/nchs/icd/icd9cm.htm [Accessed 17 December 2020].

13. Huguier M, Barrier A, Boelle PY, et al. Ischemic colitis. Am J Surg 2006;192:679-684.

14. Lee T-C, Wang H-P, Chiu H-M, et al. Male gender and renal dysfunction are predictors of adverse outcome in nonpostoperative ischemic colitis patients. J Clin Gastroenterol 2010;44:e96-e100.

15. Añón R, Boscá MM, Sanchiz V, et al. Factors predicting poor prognosis in ischemic colitis. World J Gastroenterol 2006;12:48754878 .

16. Mosele M, Cardin F, Inelmen EM, et al. Ischemic colitis in the elderly: predictors of the disease and prognostic factors to negative outcome. Scand J Gastroenterol 2010;45:428-433.

17. Chung JW, Cheon JH, Park JJ, et al. Development and validation of a novel prognostic scoring model for ischemic colitis. Dis Colon Rectum 2010;53:1287-1294.

18. Walker AM, Bohn RL, Cali C, et al. Risk factors for colon ischemia. Am J Gastroenterol 2004;9:1333-1337.

19. Chang L, Kahler KH, Sarawate C, et al. Assessment of potential risk factors associated with ischaemic colitis. Neurogastroenterol Motil 2008;20:36-42.

20. Sotiriadis J, Brandt LJ, Behin DS, et al. Ischemic colitis has a worse prognosis when isolated to the right side of the colon. Am J Gastroenterol 2007;102:2247-2252.

21. Matsumoto S, Tsuji K, Shirahama S. Clinical investigation of 41 patients with ischemic colitis accompanied by ulcer. World $J$ Gastroenterol 2007;13:1236-1239.

22. Glauser PM, Wermuth P, Cathomas G, et al. Ischemic colitis: clinical presentation, localization in relation to risk factors, and long-term results. World J Surg 2011;35:2549-2554.

23. Sherid M, Sifuentes H, Samo S, et al. Risk factors of recurrent ischemic colitis: a multicenter retrospective study. Korean J Gastroenterol 2014;63:283-291.

24. Balthazar EJ, Yen BC, Gordon RB. Ischemic colitis: CT evaluation of 54 cases. Radiology 1999;211:381-388.

25. Romano S, Romano L, Grassi R. Multidetector row computed tomography findings from ischemia to infarction of the large bowel. Eur J Radiol 2007;61:433-441.

26. Menke J. Diagnostic accuracy of multidetector CT in acute mesenteric ischemia: systematic review and meta-analysis. Radiology 2010;256:93-101. 


\section{Supplementary material}

Supplemental appendix 1 Comparison of demographic and clinical characteristics according to endoscopic grading of ischemic colitis: Group A ("minor ulcers") versus group B ("major ulcers")

\begin{tabular}{|c|c|c|c|c|c|}
\hline & $\begin{array}{l}\text { Entire population } \\
\qquad(\mathrm{n}=227)\end{array}$ & $\begin{array}{c}\text { Grade } 2 \text { or } 3, \\
\text { Group B }(\mathrm{n}=90)\end{array}$ & $\begin{array}{l}\text { Grade 1, Group A } \\
\qquad(\mathrm{n}=137)\end{array}$ & ORs $[95 \% \mathrm{CI}]$ & P-value \\
\hline \multicolumn{6}{|l|}{ Age, yo } \\
\hline mean $(\mathrm{SD})$ & $72.7(16.2)$ & $74.9(15.7)$ & $71.3(16.4)$ & $1.01(1.00-1.03)$ & 0.098 \\
\hline \multicolumn{6}{|l|}{ Gender, n (\%) } \\
\hline Male & $60(26.4)$ & $24(26.7)$ & $36(26.3)$ & 1 & \\
\hline Female & $167(73.6)$ & $66(73.3)$ & $101(73.7)$ & $1.02(0.55-1.86)$ & 0.948 \\
\hline \multicolumn{6}{|c|}{ Pain symptom, n (\%) } \\
\hline No & $38(16.7)$ & $14(15.6)$ & $24(17.5)$ & 1 & \\
\hline Yes & $189(83.3)$ & $76(84.4)$ & $112(82.5)$ & $1.15(0.57-2.42)$ & 0.699 \\
\hline \multicolumn{6}{|c|}{ Diarrhea symptom, n (\%) } \\
\hline No & $106(46.7)$ & $41(45.6)$ & $65(47.4)$ & 1 & \\
\hline yes & $121(53.3)$ & $49(54.4)$ & $72(52.6)$ & $1.08(0.63-1.85)$ & 0.780 \\
\hline \multicolumn{6}{|c|}{ Rectal Bleeding symptom, n (\%) } \\
\hline Yes & $194(85.5)$ & $76(84.4)$ & $118(86.1)$ & 1 & \\
\hline No & $33(14.5)$ & $14(15.6)$ & $19(13.9)$ & $1.14(0.53-2.41)$ & 0.724 \\
\hline \multicolumn{6}{|c|}{ History of IC, n (\%) } \\
\hline No & $199(87.7)$ & $81(90.0)$ & $118(86.1)$ & 1 & \\
\hline Yes & $26(11.5)$ & $9(10.0)$ & $17(12.4)$ & $1.81(0.73-5.13)$ & 0.225 \\
\hline Missing value & $2(0.8)$ & $0(0.0)$ & $2(1.5)$ & NE & $\mathrm{NE}$ \\
\hline \multicolumn{6}{|l|}{ Diabetes, n (\%) } \\
\hline Yes & $30(13.2)$ & $13(14.4)$ & $17(12.4)$ & 1 & \\
\hline No & $197(86.8)$ & $77(85.6)$ & $120(87.6)$ & $0.44(0.16-1.07)$ & 0.090 \\
\hline \multicolumn{6}{|c|}{ Hypertension, n (\%) } \\
\hline No & $83(36.6)$ & $28(31.1)$ & $55(40.1)$ & 1 & \\
\hline Yes & $144(63.4)$ & $62(68.9)$ & $82(59.9)$ & $1.49(0.85-2.63)$ & 0.167 \\
\hline \multicolumn{6}{|l|}{ Smoking, n (\%) } \\
\hline No & $207(91.2)$ & $80(88.9)$ & $127(92.7)$ & 1 & \\
\hline Yes & $20(8.8)$ & $10(11.1)$ & $10(7.3)$ & $1.59(0.63-4.03)$ & 0.325 \\
\hline \multicolumn{6}{|c|}{ Dyslipidemia, n (\%) } \\
\hline Yes & $65(28.6)$ & $28(31.1)$ & $37(27.0)$ & 1 & \\
\hline No & $162(71.4)$ & $62(68.9)$ & $100(73.0)$ & $0.82(0.46-1.48)$ & 0.504 \\
\hline \multicolumn{6}{|c|}{ Ischemic Vascular Disease, n (\%) } \\
\hline No & $147(64.2)$ & $53(58.9)$ & $94(68.6)$ & 1 & \\
\hline Yes & $80(35.8)$ & $37(41.1)$ & $43(31.4)$ & $1.53(0.88-2.66)$ & 0.134 \\
\hline \multicolumn{6}{|c|}{ Hemoglobin, g/dl, n (\%) } \\
\hline Mean (SD) & $13.3(1,7)$ & $13.3(1,6)$ & $13.2(1,8)$ & $1.04(0.89-1.22)$ & 0.639 \\
\hline \multicolumn{6}{|c|}{ Platelets modification, n (\%) } \\
\hline No & $15(6.6)$ & $3(3.3)$ & $12(8.8)$ & 1 & \\
\hline Yes & $212(93.4)$ & 87 (96.7) & $125(91.2)$ & $2.78(0.85-12.5)$ & 0.121 \\
\hline
\end{tabular}

(Contd) 


\begin{tabular}{|c|c|c|c|c|}
\hline $\begin{array}{l}\text { Entire population } \\
\qquad(\mathrm{n}=227)\end{array}$ & $\begin{array}{c}\text { Grade } 2 \text { or } 3, \\
\text { Group B }(n=90)\end{array}$ & $\begin{array}{c}\text { Grade 1, Group A } \\
(\mathrm{n}=137)\end{array}$ & ORs [95\% CI] & P-value \\
\hline
\end{tabular}

\begin{tabular}{|c|c|c|c|c|c|}
\hline \multicolumn{6}{|l|}{ Lactate elevation $\mathrm{n}(\%)$} \\
\hline 0 & $189(83.3)$ & $74(82.2)$ & $115(83.9)$ & 1 & \\
\hline 1 & $20(8.8)$ & $10(11.1)$ & $10(7.3)$ & $1.55(0.61-3.96)$ & 0.349 \\
\hline 2 & $18(7.9)$ & $6(6.7)$ & $12(8.8)$ & $0.78(0.26-2.09)$ & 0.628 \\
\hline \multicolumn{6}{|l|}{ Lipase, n (\%) } \\
\hline 0 & $25(11.0)$ & $10(11.1)$ & $15(10.9)$ & 1 & \\
\hline 1 & $191(84.1)$ & $76(84.4)$ & $115(83.9)$ & $0.99(0.43-2.39)$ & 0.984 \\
\hline 2 & $11(4.9)$ & $4(4.5)$ & $7(5.2)$ & $0.86(0.18-3.65)$ & 0.837 \\
\hline \multicolumn{6}{|l|}{ Oral Contraceptives, n (\%) } \\
\hline 0 & $103(45.4)$ & $44(48.9)$ & $59(43.1)$ & 1 & \\
\hline 1 or 2 & $124(54.6)$ & $46(51.1)$ & $78(56.9)$ & $0.79(0.46-1.35)$ & 0.389 \\
\hline \multicolumn{6}{|c|}{ Leukocytosis or creatinine $\geq 1.5 \mathrm{mg} / \mathrm{dL}, \mathrm{n}(\%)$} \\
\hline No & $77(33.9)$ & $23(25.6)$ & $54(39.4)$ & 1 & \\
\hline Yes & $150(66.1)$ & $67(74.4)$ & $83(60.6)$ & $1.90(1.07-3.44)$ & 0.032 \\
\hline \multicolumn{6}{|l|}{ Colon location, n (\%) } \\
\hline Rectum-sigmoid colon & $69(30.4)$ & $25(27.8)$ & $44(32.2)$ & 1 & \\
\hline Descending colon & $126(55.5)$ & $51(56.7)$ & $75(54.7)$ & $1.20(0.66-2.21)$ & 0.561 \\
\hline Proximal colon & $32(14.1)$ & $14(15.5)$ & $18(13.1)$ & $1.38(0.58-3.22)$ & 0.471 \\
\hline \multicolumn{6}{|c|}{ Length of hospitalization, days } \\
\hline Mean (SD) & $5.2(1.7)$ & $5.5(1.9)$ & $5.1(1.5)$ & $1.13(0.96-1.32)$ & 0.149 \\
\hline
\end{tabular}

SD, standard deviation; yo, years old; OR, odd ratio 
Supplemental appendix 2 Comparison of demographic and clinical characteristics according to leukocytes count and creatinine levels: abnormal, either alteration of leukocytes count or creatinine levels $\geq 1.5 \mathrm{mg} /, \mathrm{n}(\%)$ vs. normal, patients without alteration of leukocytes count and creatinine levels $<1.5 \mathrm{mg} / \mathrm{dL}$

\begin{tabular}{|c|c|c|c|c|c|}
\hline & Entire population $(\mathrm{n}=227)$ & Abnormal $(\mathrm{n}=150)$ & Normal 1 (77) & ORs $[95 \% \mathrm{CI}]$ & P-value \\
\hline \multicolumn{6}{|l|}{ Age, yo } \\
\hline mean $(\mathrm{SD})$ & $72.7(16.2)$ & $72.6(16.7)$ & $73.0(15.3)$ & $1.00(0.98-1.02)$ & 0.862 \\
\hline \multicolumn{6}{|l|}{ Gender, n(\%) } \\
\hline Female & $60(26.4)$ & $44(29.3)$ & $16(20.8)$ & 1 & \\
\hline Male & $167(73.6)$ & $106(70.7)$ & $61(79.2)$ & $1.58(0.84-3.11)$ & 0.168 \\
\hline \multicolumn{6}{|c|}{ History of IC, n (\%) } \\
\hline No & $199(87.7)$ & $129(86.0)$ & $70(90.9)$ & 1 & \\
\hline Yes & $26(11.5)$ & $20(13.3)$ & $6(7.8)$ & $1.51(0.64-3.98)$ & 0.369 \\
\hline Missing value & $2(0.8)$ & $1(0.7)$ & $1(1.3)$ & $\mathrm{NE}$ & $\mathrm{NE}$ \\
\hline \multicolumn{6}{|l|}{ Diabetes, n (\%) } \\
\hline Yes & $30(13.2)$ & $24(16.0)$ & $6(7.8)$ & 1 & \\
\hline No & $197(86.8)$ & $126(84.0)$ & $71(92.2)$ & $0.44(0.16-1.07)$ & 0.090 \\
\hline \multicolumn{6}{|c|}{ Hypertension, n (\%) } \\
\hline No & $83(36.6)$ & $48(32.0)$ & $35(45.5)$ & 1 & \\
\hline Yes & $144(63.4)$ & $102(68.0)$ & $42(54.5)$ & $1.77(1.01-3.12)$ & 0.047 \\
\hline \multicolumn{6}{|l|}{ Smoking, n (\%) } \\
\hline No & $207(91.2)$ & $136(90.7)$ & $71(92.2)$ & 1 & \\
\hline Yes & $20(8.8)$ & $14(9.3)$ & $6(7.8)$ & $0.82(0.28-2.14)$ & 0.698 \\
\hline \multicolumn{6}{|c|}{ Dyslipidemia, n (\%) } \\
\hline Yes & $65(28.6)$ & $48(32.0)$ & $17(22.1)$ & 1 & \\
\hline No & $162(71.4)$ & $102(68.0)$ & $60(77.9)$ & $0.60(0.31-1.12)$ & 0.119 \\
\hline \multicolumn{6}{|c|}{ Ischemic Vascular Disease, n (\%) } \\
\hline No & $147(64.2)$ & $91(60.7)$ & $56(72.7)$ & 1 & \\
\hline Yes & $80(35.8)$ & $59(39.3)$ & $21(27.3)$ & $1.73(0.96-3.19)$ & 0.073 \\
\hline \multicolumn{6}{|c|}{ Hemoglobin, g/dl, n (\%) } \\
\hline mean, (SD) & $13.3(1,8)$ & $13.3(1,6)$ & $13.3(1,9)$ & $1.01(0.86-1.18)$ & 0.925 \\
\hline \multicolumn{6}{|l|}{ Platelets, n (\%) } \\
\hline No & $15(6.6)$ & $11(7.3)$ & $4(7.2)$ & 1 & \\
\hline Yes & $212(93.4)$ & $139(92.7)$ & $73(92.8)$ & $0.69(0.19-2.10)$ & 0.541 \\
\hline \multicolumn{6}{|l|}{ Lactate, n (\%) } \\
\hline 0 & $189(83.3)$ & $122(81.4)$ & $67(87.0)$ & 1 & \\
\hline 1 & $20(8.8)$ & $14(9.3)$ & $6(7.8)$ & $1.28(0.49-3.8)$ & 0.628 \\
\hline 2 & $18(7.9)$ & $14(9.3)$ & $4(5.2)$ & $1.92(0.65-6.9)$ & 0.266 \\
\hline \multicolumn{6}{|l|}{ Lipasi, n (\%) } \\
\hline 0 & $25(11.0)$ & $15(10.0)$ & $10(13.0)$ & 1 & \\
\hline 1 & $191(84.1)$ & $128(85.3)$ & $63(81.8)$ & $1.35(0.56-3.45)$ & 0.487 \\
\hline 2 & $11(4.9)$ & $7(4.7)$ & $4(5.2)$ & $1.17(0.27-5.43)$ & 0.837 \\
\hline \multicolumn{6}{|c|}{ Length of hospitalization, days } \\
\hline Mean (SD) & $5.2(1.7)$ & $5.3(1.7)$ & $5.1(1.6)$ & $1.08(0.92-1.30)$ & 0.332 \\
\hline \multicolumn{6}{|c|}{ ICs grade (dichotomized) } \\
\hline 1 & $137(60.4)$ & $83(55.3)$ & $54(70.1)$ & 1 & \\
\hline 2 or 3 & $90(39.6)$ & $67(44.7)$ & $23(29.9)$ & $1.90(1.07-3.44)$ & 0.032 \\
\hline
\end{tabular}

